\title{
Tumor hepático con vías biliares normales en un paciente con síndrome de Alagille: a propósito de un caso
} Liver mass containing normal bile ducts in an Alagille patient: a case report

\author{
Estud. Med. Stefanie Parisien-La Salle ${ }^{a}$, Dr. Justin Côté-Daigneault ${ }^{b}$, Dr. Laurent Garelc, \\ Dr. Luc Laurier Oligny y Dr. Fernando Álvarez ${ }^{c}$
}

\section{RESUMEN}

En este artículo se informa el caso de un paciente con síndrome de Alagille, que desarrolló una lesión de crecimiento rápido en el lóbulo caudado del hígado cirrótico. Se realizó el seguimiento riguroso del tumor aunque, desde el punto de vista radiológico, no parecía ser maligno. En el estudio por resonancia magnética (RM), no se observó ningún criterio diagnóstico de carcinoma hepatocelular; no obstante, se realizó una biopsia de la lesión y del hígado debido al rápido crecimiento del tumor. Los resultados del informe anatomopatológico indicaron desarrollo normal de los conductos biliares en el tumor y escasez de conductos biliares en la segunda muestra del hígado. Describiremos este caso y propondremos una interpretación de estos resultados.

Palabras claves: sindrome de Alagille, conductos biliares, escasez de conductos biliares interlobulares, hígado, lóbulo caudado.

http:/ /dx.doi.org/10.5546/aap.2015.e223

\section{INTRODUCCIÓN}

El síndrome de Alagille (SAG) es una enfermedad autosómica dominante con expresión variable ocasionada por mutaciones localizadas en los genes JAGGED1 y NOTCH $2^{1}$, que participan en la vía asociada con el desarrollo normal de los conductos biliares. La característica principal es la escasez de conductos biliares interlobulares, lo que provoca colestasis crónica en el 91\% de los pacientes. Otras anomalías importantes características de este síndrome son: cardiopatía congénita $(85 \%)$, vértebras en alas de mariposa $(87 \%)$, embriotoxón $(88 \%)$ y rasgos faciales

a. Universidad de Montreal.

b. CHUM (Centro Hospitalario de la Universidad de Montreal).

c. Sainte-Justine Hospital.

Correspondencia:

Estud. Med. Stefanie Parisien-La Salle:

stefanie.parisien-la.salle@umontreal.ca

Financiamiento: Ninguno.

Conflicto de intereses: ninguno que declarar.

Recibido: 3-1-2015

Aceptado: 2-3-2015 característicos (95\%). ${ }^{2}$ Es posible establecer el diagnóstico clínico cuando el paciente tiene al menos tres de estos signos importantes. ${ }^{2}$

\section{CASO CLÍNICO}

Se hospitalizó al paciente de cuatro semanas de vida por colestasis neonatal y heces pálidas. En las pruebas funcionales hepáticas iniciales, se observó una lesión hepática y colestasis obstructiva (ALAT: 74 U/L [N: 5-34], ASAT: 154 U/L [N: 11-43], GGT: 81 U/L [N:3-43]), y un nivel elevado de bilirrubina conjugada (109 umol/L [N:0-4]). El SAG se diagnosticó un mes después debido a manifestaciones clínicas adicionales, que incluyeron la presencia de una vértebra en alas de mariposa en $\mathrm{T} 5$, rasgos faciales característicos, estenosis pulmonar periférica e ictericia persistente. Una biopsia de hígado reveló un cuadro inespecífico de colestasis neonatal, asociado con escasez de conductos biliares interlobulares. Cuatro años después, se identificó la mutación JAG1 r184c + que confirmó el diagnóstico inicial de SAG parcial.

A los 12 años, el paciente comenzó a presentar heterogeneidad hepática e hipertrofia del lóbulo caudado.

Cuatro años después, la ecografía reveló la presencia de una lesión heterogénea de $6,5 \mathrm{~cm}$ x 4,4 cm, localizada en el lóbulo caudado del hígado. En ese momento, el diagnóstico de hiperplasia nodular focal (HNF) parecía ser el más probable.

Durante el año siguiente, el tumor creció en tamaño.

Se realizó entonces una RM abdominal (Figura 1). Las imágenes mostraron que el tumor había alcanzado $10,7 \mathrm{~cm} \times 12,5 \mathrm{~cm}$ x 6,9 cm y estaba bien delimitado. Tras la administración de gadolinio, el tumor tuvo un realce uniforme y no se observaron signos de pérdida temprana del realce del material de contraste. El tumor no era de contenido graso. No se observó adenopatía hiliar.

El diámetro transversal del bazo era de $23 \mathrm{~cm}$, lo que indicaba el desarrollo de hipertensión 
portal. Los resultados clínicos, bioquímicos y radiológicos no concordaban con los criterios establecidos para carcinoma hepatocelular. El valor de la alfafetoproteína se mantuvo normal; se realizó una biopsia de los lóbulos caudado y derecho que reveló que el tumor estaba compuesto por hígado normal, sin presencia de ductopenia. En la muestra, seis de los siete espacios portales fueron normales y en el séptimo se observó hepatitis leve sin fibrosis. Los hepatocitos presentaron colestasis intracitoplasmática leve que se describió como moderada en la biopsia de hígado normal (Figura 2).

\section{DISCUSIÓN}

Se considera que el SAG es una enfermedad crónica con presencia de ductopenia.

El mecanismo subyacente a la escasez de conductos biliares no se comprende por completo en los seres humanos. En células normales, el ligando JAGGED1 activa los receptores $\mathrm{NOTCH}$ en hepatoblastos bipotenciales, lo que da lugar a la diferenciación en la formación de colangiocitos y conductos biliares intrahepáticos. ${ }^{3}$ La aparición espontánea de conductos biliares normales es un fenómeno poco frecuente.

El compromiso vascular parece ser importante

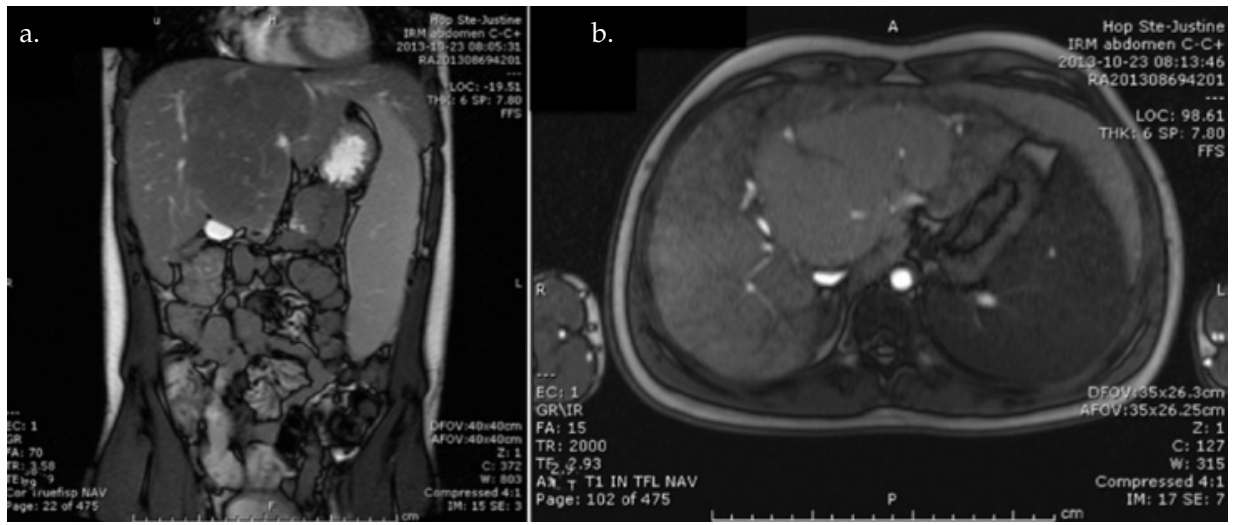

Figura 2. Hematoxilina-Eosina x 100: a) Fibrosis extensa con micronódulos en el lóbulo derecho del hígado; b) Hígado normal, en la biopsia del lóbulo caudado. Análisis de inmunohistoquímica que detecta la expresión de citoqueratina 19; c) Ausencia de conductos biliares interlobulares en el lóbulo derecho; d) Presencia de conductos biliares interlobulares en el hígado normal
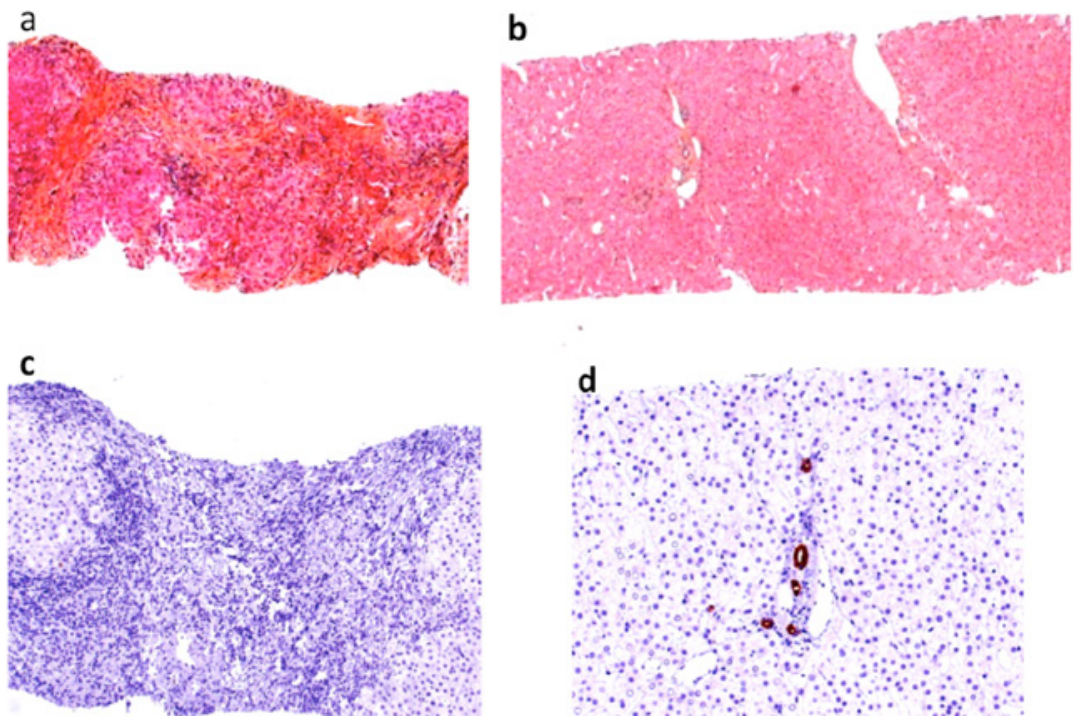
en el desarrollo de conductos anómalos. Es más, se ha demostrado, en ratones, que la mutación del gen JAGGED1 en el mesénquima de la vena porta causa el fenotipo hepático del SAG. ${ }^{4}$ Esto puede explicarse debido a que los conductos biliares se originan a partir de células bipotenciales que recubren el mesénquima de la vena porta. ${ }^{5}$ En el SAG, el gen mutado altera la señalización a los hepatoblastos, causando el desarrollo anómalo de los colangiocitos. De modo que para que los conductos biliares hepáticos sean normales, la mutación debe preservar las células que fueron destinadas a vascularizar el lóbulo caudado, dado que el paciente podría tener mosaicismo congénito. Esta situación es posible debido a que el lóbulo caudado es independiente, desde el punto de vista embrionario y anatómico, de los lóbulos derecho e izquierdo del hígado y del hilio hepático principal. ${ }^{6}$ Otra posibilidad es que exista una vía alternativa para la formación de conductos. La regeneración de los conductos biliares teóricamente es posible sin la señalización $\mathrm{NOTCH}$; sin embargo, solo se ha identificado en experimentos con múridos. ${ }^{3}$

El aumento del tamaño del lóbulo caudado puede atribuirse al drenaje venoso del hígado. El lóbulo caudado drena directamente en la vena cava inferior, ya que el resto del hígado drena primero en las venas hepáticas. El hígado cirrótico causa la obstrucción de las venas hepáticas, provocando un aumento en el flujo sanguíneo del lóbulo caudado. Dada la anatomía vascular particular del lóbulo caudado durante la vida fetal, conjeturamos que, en este paciente, el gen JAGGED normal solo se expresó en el lóbulo caudado, lo que permitió el desarrollo normal de los conductos biliares. ${ }^{7}$

En conclusión, el síndrome de Alagille continúa siendo una enfermedad grave, con una tasa de supervivencia global a 20 años del $62 \% .{ }^{8}$ Esperamos que este caso pueda aportar claridad acerca de la patogenia del SAG y ayude a mejorar el control y tratamiento de esta enfermedad.

\section{REFERENCIAS}

1. Ciocca M, Álvarez F. Síndrome de Alagille. Arch Argent Pediatr 2012;110(6):509-15.

2. AlagilleD, Estara A, etal.Syndromic paucity of interlobular bile ducts (Alagille syndrome or arteriohepatic dysplasia): review of 80 cases. J Pediatr 1987;110(2):195-200.

3. Walter TJ, VanderpoolC, Cast AE,HuppertSS. Intrahepatic bile duct regeneration in mice does not require Hnf6 or Notch signaling through Rbpj. Am J Pathol 2014;184(5): 1479-88.

4. Hofmann JJ, Zovein AC, Koh H, Radtke F, et al. Jagged1 in the portal vein mesenchyme regulates intrahepatic bile duct development: insights into Alagille syndrome. Development 2010;137(23):4061-72.

5. Desmet VJ. Ludwig symposium on biliary disorders. Part I. Pathogenesis of ductal plate abnormalities. Mayo Clinic Proc 1998;73(1):80-9.

6. Abdalla EK, Vauthey JN, Couinaud C. The caudate lobe of the liver: implications of embryology and anatomy for surgery. Surg Oncol Clin N Am 2002;11(4):835-48.

7. Lykavieris P,Hadchouel M,Chardot C, BernardO.Outcome of liver disease in children with Alagille syndrome: a study of 163 patients. Gut 2001;49(3):431-5.

8. Dodds WJ, EricksonSJ, Taylor AJ, Lawson TL, et al. Caudate lobe of the liver: anatomy, embryology, and pathology. AJR Am J Roentgenol 1990;154(1):87-93. 